ORIGINAL ARTICLE

\title{
A study of Ascitic Fluid of Cirrhotic patients with Spontaneous Bacterial Peritonitis; common microorganisms and their antibiotic Senstivity
}

\author{
AIJAZ ZEESHAN KHAN CHACHAR ${ }^{1}$, MIQDAD HAIDER ${ }^{2}$, SAJJAD ALI ${ }^{3}$, NAZISH YAQOOB ${ }^{4}$, NAVEED ASLAM LASHARI ${ }^{5}$, \\ HAFIZ BASHIR AHMED 6 \\ ${ }^{1}$ Senior Registrar, Fatima Memorial Hospital College of Medicine \& Dentistry, Lahore. \\ ${ }^{2}$ Medical officer, Social Security Hospital, Lahore \\ ${ }^{3}$ Consultant, Eastern Maine Medical Center, USA \\ ${ }^{4}$ Medical Officer, Mian Mir Hospital, Lahore \\ ${ }^{5}$ Classified Medical specialist and Rheumatologist PAF Hospital, Islamabad \\ ${ }^{6}$ Assistant Professor, Liaquat University Hospital, Hyderabad \\ Correspondence to Dr. Aijaz Zeeshan Khan ChacharEmail: dr_aijaz84@hotmail.com, Cell: 0333-2612096
}

\begin{abstract}
Background: Spontaneous bacterial peritonitis (SBP) is an acute infection of otherwise sterile ascitic fluid in patients with decompensated liver cirrhosis. Gram negative bacteria are considered the main causative microorganisms of SBP. However, widespread use of antibiotics in cirrhotic patients has changed the microbial spectrum and the sensitivity patterns.

Aim: To determine the frequency of different microorganisms and their sensitivity patterns in ascitic fluid of cirrhotic patients with spontaneous bacterial peritonitis and to see the impact of age, gender and duration of SBP on these patterns.

Study design and duration: It was a prospective observational study conducted at Fatima Memorial Hospital, Lahore from December 2015 to December 2016.

Methods: A total of 200 patients with clinical suspicion of SBP were enrolled in the study. Ascitic fluid sample was obtained within 6 hours of hospitalization and was sent to hospital laboratory. Culture reports were reviewed to determine the frequency of different microorganism as well as their sensitivity patterns to different antibiotics.

Results: Out of 200 patients, the culture was positive in 113(56.53\%) patients. Escherichia coli was seen in 35 $(31.2 \%)$ patients, Acinobacter Spp was present in 18 (15.3\%), Streptococcus in 15 (13.4\%), Enterococcus in 14 (12.1\%), Staphylococcus aureus in 13 (11.4\%), MRSA in 12 (10.8\%), and K. Pneumonia in 6 (5.7\%) patients. Ceftazidime was sensitive in $73(64.9 \%)$ cases, Cefotaxime was sensitive in $55(49 \%)$, Ceftriaxone was sensitive in 50 (43.9\%), Ciprofloxacin was sensitive in 49 (43.3\%), Amikacin was sensitive in 36 (31.8\%)

Conclusion: The most frequent organism in ascitic fluid of SBP patients was $E$ Coli, and the most sensitive antibiotic was ceftazidime.

Keywords: Microbial Spectrum, Sensitivity Pattern,Spontaneous Bacterial Peritonitis (SBP), Ascitic Fluid
\end{abstract}

\section{INTRODUCTION}

Spontaneous bacterial peritonitis (SBP) is a frequent complication of decompensated cirrhosis, affecting both adult and paediatric patients with ascites.,2 Bacterial translocation, altered immunity in cirrhotic patients and low ascites fluid albumin are the key factors in the development of SBP.5-7 Ascitic fluid polymorphonuclear neutrophil (PMN) count more than $250 / \mathrm{ml}$ is used as diagnostic criteria of SBP, as the culture is positive only in $40 \%$ of patients. ${ }^{3}$ The risk of developing SBP in cirrhotic patients with ascites is estimated to be $10 \%-30 \%$. $^{4,5}$ SBP is one of the leading causes of morbidity and mortality in patients with cirrhosis. ${ }^{3-5}$ Early diagnosis and a prompt antibiotic therapy can decrease the mortality rate from $80 \%$ to a $20-$ $30 \%$. ${ }^{6}$ Historically, gram-negative bacteria were known as the most prevalent cause of SBP ${ }^{9}$ with Escherichia coli as the commonest organisms isolated and most of the international societies recommended third-generation cephalosporin as empirical treatment of SBP and norfloxacin for secondary prophylaxis. ${ }^{10,11}$ However, the

Received on 15-03-2021

Accepted on 23-06-2021 organisms and sensitivity patterns in SBP have been changed considerably in the last few years. Gram-positive and drug-resistant bacteria are being detected increasingly in ascitic fluid of SBP patients. $3,8,9,12-14$ This change in microbiology as well as sensitivity pattern has been attributed to widespread and injudicious use of antibiotics in cirrhotic patients. These observations have raised questions about the use of commonly recommended empirical antibiotics in SBP. The microbial spectrum and sensitivity patterns in SBP have changed considerably in the last few years, worldwide, therefore we tried to evaluate the common microorganisms as well their sensitivity in our local population.

\section{MATERIAL \& METHODS}

It was a prospective observational study carried out in the department of Medicine, Fatima Memorial Hospital, Lahore from December 2015 to December 2016. The nonprobability consecutive sampling technique was used to include the patients. Sample size of 200 cases was calculated using $90 \%$ confidence interval, $5 \%$ margin of error and taking expected culture positivity of $60 \%$. Male and female patients aged 20-60 years having 
decompensated cirrhosis and clinical suspicion of spontaneous bacterial peritonitis based on history \& examination were included in the study. High risk patients i.e. uncontrolled diabetes (BSR $>200 \mathrm{mg} / \mathrm{dl}$ ), uncontrolled hypertension (BP $>140 / 90 \mathrm{mmHg}$ ), deranged RFTs (serum creatinine $>1.2 \mathrm{mg} / \mathrm{dl}$ ) or cardiac problem (abnormal ECG), were excluded from the study. Patients with a history of peritoneal paracentesis or use of antibiotics in the last 4 weeks, secondary peritonitis (perforation of viscus or infective focus on USG), tuberculosis or malignancy (on history / medical record) were also excluded from the study. Data collection: After taking approval from institutional review board, informed written consent was obtained from each patient. The demographic information (name, age, sex and duration of SBP) was noted. $10 \mathrm{ml}$ of ascitic fluid was obtained during first 6hours of hospitalization. Sample was sent to the laboratory of the hospital. SBP was defined as a PMN count equal to or greater than $250 / \mathrm{ml}$ in ascitic fluid or ascitic fluid culture positive for one or more organisms. Culture reports were followed to check the type of microorganism in ascitic fluid and their sensitivity patterns.

Data Analysis: The data was analysed statistically by using SPSS version 24.0 Quantitative variables like age and duration of SBP was presented in form of mean \pm S.D. Qualitative variables like gender, microbial spectrum\& antibiotic sensitivity were presented in form of frequency and percentage. Data was stratified for age, gender and duration of SBP. Post-stratification, chi-square was applied. $P$ value $\leq 0.05$ was taken as significant.

\section{RESULTS}

A total 200 cases were enrolled in the study. Mean age of the patients was $40.42 \pm 11.31$. 143 patients $(71.5 \%)$ were male and 57 patients $(28.5 \%)$ were females. The mean duration of decompensated cirrhosis was $5.45 \pm 6.50$ years. $55(27.3 \%)$ patients were having Child A cirrhosis, 78 $(39.2 \%)$ patients were having Child B cirrhosis and 67 (33.5\%) patients were having Child C cirrhosis. The culture was positive in 113(56.53\%) patients.(Table-1) Escherichia coli was the most frequent microorganism seen in $35(31.2 \%)$ patients, Acinobacter Spp was present in 18 $(15.3 \%)$, Streptococcus in $15(13.4 \%)$, Enterococcus in 14 $(12.1 \%)$, Staphylococcus aureus in 13 (11.4\%), MRSA in $12(10.8 \%)$, and K. Pneumonia in 6(5.7\%) patients. (Table2) Ceftazidime was sensitive in $73(64.9 \%)$ cases, Cefotaxime was sensitive in 55(49\%), Ceftriaxone was sensitive in 50(43.9\%), Ciprofloxacin was sensitive in $49(43.3 \%)$, Amikacin was sensitive in $36(31.8 \%)$, Co Amoxiclave was sensitive in $29(25.5 \%)$ and Imipenum was sensitive in 19 (16.6\%) cases (Table-3).

Table.1: Baseline Characteristics (Age, Gender, disease duration, child class and culture report) of the Study Participants

\begin{tabular}{|c|c|c|c|c|}
\hline Parameter & & $\mathrm{N}=\mathbf{2 0 0}$ & Minimum & Maximum \\
\hline \multirow{2}{*}{ Gender } & Male (\%) & $143(71.5)$ & & \\
\hline & Female (\%) & $57(28.5)$ & & \\
\hline Age & Mean \pm SD & $40.42 \pm 11.31$ & 20 & 60 \\
\hline Disease Duration & Mean \pm SD & $5.41 \pm 6.50$ & 1 & 6 \\
\hline \multirow[t]{3}{*}{ Child Class } & $\mathrm{A}(\%)$ & $55(27.3)$ & & \\
\hline & $\mathrm{B}(\%)$ & 78 (39.2) & & \\
\hline & C (\%) & $67(33.5)$ & & \\
\hline \multirow[t]{2}{*}{ Culture Report } & Positive(\%) & $113(56.53 \%)$ & & \\
\hline & Negative(\%) & $87(43.47)$ & & \\
\hline
\end{tabular}

Table 2: Spectrum of Micro-organisms \& Impact of Age, Gender \& Duration of Disease

\begin{tabular}{|c|c|c|c|c|c|c|c|c|c|c|}
\hline \multirow[b]{2}{*}{ Organisms } & \multicolumn{2}{|c|}{ Age (years) } & \multirow[t]{2}{*}{ p-value } & \multicolumn{2}{|c|}{ Gender } & \multirow[t]{2}{*}{ p-value } & \multicolumn{2}{|c|}{ Disease Duration (years) } & \multirow[b]{2}{*}{$\begin{array}{c}\mathbf{P} \\
\text { value }\end{array}$} & \multirow[b]{2}{*}{ Total } \\
\hline & $\begin{array}{l}<30 \\
\mathrm{n}=50\end{array}$ & $\begin{array}{c}\geq 30 \\
n=150\end{array}$ & & $\begin{array}{c}\text { Male } \\
n=143\end{array}$ & $\begin{array}{c}\text { Female } \\
n=57\end{array}$ & & $\begin{array}{c}\text { Below } 3 \\
n=103\end{array}$ & $\begin{array}{c}\text { Above } 3 \\
n=97\end{array}$ & & \\
\hline Escherichia coli & 16 & 19 & 0.548 & 24 & 11 & 0.912 & 20 & 15 & 0.204 & 35 \\
\hline Acinobacter Spp & 2 & 16 & 0.559 & 15 & 3 & 0.722 & 10 & 8 & 0.282 & 18 \\
\hline MRSA & 3 & 9 & 0.811 & 8 & 4 & 0.272 & 5 & 7 & 0.136 & 12 \\
\hline Staph. Aureus & 3 & 10 & 0.570 & 9 & 4 & 0.325 & 8 & 5 & 0.983 & 13 \\
\hline Streptococcus & 3 & 12 & 0.644 & 4 & 11 & 0.074 & 7 & 8 & 0.304 & 15 \\
\hline Enterococcus & 2 & 12 & 0.832 & 9 & 5 & 0.176 & 6 & 8 & 0.353 & 14 \\
\hline K. Pneumonia & 1 & 5 & 0.397 & 2 & 4 & 0.250 & 2 & 4 & 0.400 & 6 \\
\hline
\end{tabular}

Table 3: Patterns of Antibiotic Sensitivity \& Impact of Age, Gender \& Duration of Disease

\begin{tabular}{|c|c|c|c|c|c|c|c|c|c|c|}
\hline \multirow[b]{2}{*}{ Antibiotics } & \multicolumn{2}{|c|}{ Age (years) } & \multirow[t]{2}{*}{$p$-value } & \multicolumn{2}{|c|}{ Gender } & \multirow[t]{2}{*}{$p$-value } & \multicolumn{2}{|c|}{ Disease Duration (years) } & \multirow[b]{2}{*}{ p-value } & \multirow[b]{2}{*}{ Total } \\
\hline & $\begin{array}{l}<30 \\
n=50\end{array}$ & $\begin{array}{c}\geq 30 \\
n=150\end{array}$ & & $\begin{array}{c}\text { Male } \\
n=143\end{array}$ & $\begin{array}{c}\text { Female } \\
\mathrm{n}=57\end{array}$ & & \begin{tabular}{|c|} 
Below 3 \\
$n=103$
\end{tabular} & $\begin{array}{c}\text { Above } 3 \\
n=97\end{array}$ & & \\
\hline Ceftazidime & 28 & 45 & 0.409 & 49 & 24 & 0.142 & 38 & 35 & 0.979 & 73 \\
\hline Cefotaxime & 14 & 41 & 0.567 & 38 & 17 & 0.876 & 28 & 27 & 0.798 & 55 \\
\hline Ceftriaxone & 21 & 19 & 0.471 & 33 & 17 & 0.667 & 38 & 12 & 0.039 & 50 \\
\hline Ciprofloxacin & 17 & 32 & 0.718 & 35 & 14 & 0.964 & 24 & 25 & 0.575 & 49 \\
\hline Amikacin & 17 & 19 & 0.441 & 27 & 09 & 0.623 & 20 & 16 & 0.844 & 36 \\
\hline Co-Amoxiclav & 8 & 21 & 0.219 & 20 & 09 & 0.770 & 15 & 14 & 0.677 & 29 \\
\hline Imipenem & 4 & 15 & 0.289 & 12 & 7 & 0.930 & 11 & 8 & 0.539 & 19 \\
\hline
\end{tabular}




\section{DISCUSSION}

In our study the microorganism Escherichia coli was the most frequent microorganism present in 35 (31.2\%) patients while Klebsiella Pneumonia was the least frequent microorganism observed only in $6(5.7 \%)$ patients. Antibiotic sensitivity results of our study showed that the Ceftazidime was the most sensitive antibiotic in 73 (64.9\%) patients, while Imipenem was the least sensitive antibiotic only in 19 (16.6\%) patients. A local study performed at lady reading hospital Peshawar also reported E.coli as most frequent organism in $30 \%$ patients. $\mathrm{K}$ Pneumonia was detected in $14 \%$, S. pneumonia in $16 \%$, Enterobacter in $8 \%, S$ aureus in $4 \%$, and Enterococcus in $4 \%$ patients. The sensitivities of all these organisms collectively were ceftriaxone $(70 \%)$, cefotaxime $(70 \%)$, ciprofloxacin $(66 \%)$, co-amoxiclave $(58 \%) \cdot{ }^{15} \mathrm{~A}$ study by Sheikhbahaei et al showed that most of the $\mathrm{E}$. coli isolates were sensitive to piperacillin-tazobactam, imipenem, ceftizoxime,amikacin and gentamicin, and only $20-30 \%$ of $\mathrm{E}$. coli isolates showed sensitivity to cefotaxime and ceftazidime.The sensitivity to ceftriaxone was $43.4 \% .{ }^{16}$ Aretrospective study conducted at Germany showed that the frequency of enterococcal infections in SBPhas increased from $11 \%$ to $35 \%$ which demonstrated increased resistance to cephalosporins. ${ }^{17} \mathrm{~A}$ study by Najeeb et al showed Staphylococcus aureus in $26.9 \%$ cases andE. coli in $23.1 \%$ cases. ${ }^{18}$ The Changes in the pattern of resistance rate to the antibiotics from 2005-2011, were as ciprofloxacin (30, $59.8 \%)$, cefotaxime $(62.5 \%, 85.7 \%)$,ceftazidime $(73 \%$, $82.1 \%)$, amikacin $(19.8 \%, 29 \%)$, ofloxacin $(36.8 \%, 50 \%)$, and oxacillin (35\%, 51.6\%). Ceftriaxone showed least change in resistant strains $(57.8 \%, 59 \%) .{ }^{4} \mathrm{~A}$ study conducted in Korea advocated cefotaxime as a choice of primary empirical antibiotic inSBP. ${ }^{9}$ Another study in Spain indicated that ceftriaxone is effectivein $73 \%$ of patients. ${ }^{19}$ In a study conducted by Akhtar et al amikacin \& imipenem showed low resistance(21.3\%\&26.1\%) and cefotaxime, ceftriaxone \& ceftazidime showed high resistance (> 60\%) while ofloxacin and ciprofloxacin $(65.9 \% \& 73.9 \%){ }^{20}$

\section{CONCLUSION}

Our study concluded that the most common bacteria in SBP samples of patients was E Coli, and the antibiotics which showed highest frequency of sensitivity pattern was ceftazidime. Moreover age, gender and duration of SBP had no significant impact on microbial spectrum and sensitivity pattern of a particular antibiotic.

Limitations: Our study was a single centre study with relatively smaller sample size so results of this study can't be generalized to whole population of the country.

Recommendations: Multicenter studies are need of the day to be conducted among all the provinces of Pakistan with larger sample size so their results will be representing the regional differences in microbes and can help the health policy makers to devise a strategy to get the recommendations of that study need to be implemented as national guidelines for each province to improve the overall health care quality \& delivery in the country.

Contribution of authors: AZKC: Conception of the study, Data collection, Review of literature, Review of manuscript,
Development of Research Methodology Design, Study Design, Data analysis \& Data Interpretation, Article writing, Review of Literature, Drafting article, final approval of manuscript, MH: Data collection, Review of literature, drafting article, SA: Review of literature, Drafting article, Article writing, NY: Data collection, Review of literature, drafting article, NAL: Data collection, Review of literature, final approval of manuscript, ,HBA: Data collection, Review of literature

\section{REFERENCES}

1. Balan G, Trifan A, Botezatu D, Anton C. [Spontaneous bacterial peritonitis: a severe complication of liver cirrhosis]. Rev Med Chir Soc Med Nat lasi. 2011;115(1):38-44.

2. Lata J, Stiburek O, Kopacova M. Spontaneous bacterial peritonitis: a severe complication of liver cirrhosis. World journal of gastroenterology: WJG. 2009;15(44):5505.doi: 10.3748/wjg.15.5505

3. Gines $\mathrm{P}$, Angeli $\mathrm{P}$, Lenz $\mathrm{K}$, Moller S, Moore K, Moreu R European Association for the Study of the Liver. EASL clinical practice guidelines on the management of ascites, spontaneous bacterial peritonitis, and hepatorenal syndrome in cirrhosis. J Hepatol. 2010;53:397417./doi.org/10.1016/j.jhep.2010.05.004.

4. Sheikhbahaei S, Abdollahi A, Hafezi-Nejad N, Zare E. Patterns of antimicrobial resistance in the causative organisms of spontaneous bacterial peritonitis: a single centre, six-year experience of 1981 samples. International journal of hepatology. 2014;2014.doi.org/10.1155/2014/917856.

5. Lee JM, Han $\mathrm{KH}$, Ahn SH. Ascites and spontaneous bacterial peritonitis: an Asian perspective. Journal of gastroenterology and hepatology. 2009;24(9):1494503./doi.org/10.1111/j.1440-1746.2009.06020.x .

6. Garcia-Tsao G. Current management of the complications of cirrhosis and portal hypertension: variceal hemorrhage, ascites, and spontaneous bacterial peritonitis. Gastroenterology. 2001;120(3):72648.doi.org/10.1053/gast.2001.22580.

7. Terg R, Cobas S, Fassio E, Landeira G, Ríos B, Vasen W, et al. Oral ciprofloxacin after a short course of intravenous ciprofloxacin in the treatment of spontaneous bacterial peritonitis: results of a multicenter, randomized study. Journal of hepatology. 2000;33(4):5649.doi.org/10.1016/s0168-8278(00)80008-2.

8. Singh N, Wagener M, Gayowski T. Changing epidemiology and predictors of mortality in patients with spontaneous bacterial peritonitis at a liver transplant unit. Clinical microbiology and infection. 2003;9(6):5317.doi.org/10.1046/j.1469-0691.2003.00691-x

9. Park MK, Lee JH, Byun YH, Lee HI, Gwak GY, Choi MS, et al. Changes in the profiles of causative agents and antibiotic resistance rate for spontaneous bacterial peritonitis: an analysis of cultured microorganisms in recent 12 years. The Korean journal of hepatology. 2007;13(3):3707.doi.org/10.1016/s0168-8278(07)61842-x

10. Riggio O, Angeloni S. Ascitic fluid analysis for diagnosis and monitoring of spontaneous bacterial peritonitis. World $\mathrm{J}$ Gastroenterol.

2009;15(31):3845.doi.org/10.3748/wjg.15.3845.

11. Gunjača I, Francetić I. Prevalence and Clinical Outcome of Spontaneous Bacterial Peritonitis in Hospitalized Patients with Liver Cirrhosis: A Prospective Observational Study in Central Part of Croatia. Acta Clinica Croatica. 2010;49(1):11-8.PMID: 20635579.

12. Alexopoulou A, Papadopoulos N, Eliopoulos DG, Alexaki A, Tsiriga A, Toutouza $M$, et al. Increasing frequency of 
gram-positive cocci and gram-negative multidrug-resistant bacteria in spontaneous bacterial peritonitis. Liver Int. 2013;33(7):975-81.doi.org/10.1111/liv.12152

13. Zaman A, Kareem R, Mahmood R, Hameed K, Khan EM. Frequency of microbial spectrum of spontaneous bacterial peritonitis in established cirrhosis liver. J Ayub Med Coll Abbottabad. 2011;23(4):15-7.

14. Koulaouzidis A, Bhat S, Saeed AA. Spontaneous bacterial peritonitis. World J Gastroenterol. 2009;15(9):1042.doi.org/10.3748/wjg.15.1042.

15. Haider I, Ahmad I, Rashid A, Bashir H, Faheem M. Causative organisms and their drug sensitivity pattern in ascitic fluid of cirrhotic patients with spontaneous bacterial peritonitis. Journal of Postgraduate Medical Institute (Peshawar-Pakistan). 2011 Oct 17;22(4).

16. Sheikhbahaei S, Abdollahi A, Hafezi-Nejad N, Zare E. Patterns of Antimicrobial Resistance in the Causative Organisms of Spontaneous Bacterial Peritonitis: A Single Centre, Six-Year Experience of 1981 Samples. International
Journal of Hepatology. 2014;2014:6.doi.org/10.1155/2014/917856.

17. Reuken P, Pletz M, Baier M, Pfister W, Stallmach A, Bruns $\mathrm{T}$. Emergence of spontaneous bacterial peritonitis due to enterococci-risk factors and outcome in a 12-year retrospective study. Alimentary pharmacology \& therapeutics. 2012;35(10):1199-208.doi.org/10.1111/j.13652036.2012.05076.x

18. Najeeb S, Gillani S, Ullah R, ur Rehman A. Causative bacteria and antibiotic resistance in neonatal sepsis. J Ayub Med Coll Abbottabad. 2012;24:3-4.

19. Fernández J, Navasa M, Gómez J, Colmenero J, Vila J, Arroyo V, et al. Bacterial infections in cirrhosis: epidemiological changes with invasive procedures and norfloxacin prophylaxis. Hepatology. 2002;35(1):1408.doi.org/10.1053/jhep.2002.30082.

20. Akhtar N. Hospital acquired infections in a medical intensive care unit. J Coll Physicians Surg Pak. 2010;20(6):386-90. 